\title{
Snow-pillow: creation experience and prototype operation
}

\author{
Aleksandr Minnegaliev ${ }^{*}$, Ruslan Rakhimov², Ruslan Suleimanov ${ }^{3}$, and Mansur \\ Gainanshin ${ }^{1}$ \\ ${ }^{1}$ Bashkir State University, 32 Z. Validi St., 450076, Ufa, Russia \\ ${ }^{2}$ Federal State Budgetary Institution "Bashkir UGMS”, 25/2 R. Sorge St., 450059, Ufa, Russia \\ ${ }^{3}$ Ufa Institute of Biology UFRC RAS, 69 Prospekt Oktyabrya St., 450054, Ufa, Russia
}

\begin{abstract}
A snow-pillow (or snow-measuring pillow) is a device designed to directly determine the snow water equivalent in the snow cover by measuring the weight or pressure of the snowfall. Snow-pillows allow collecting, accumulating and transmitting information about snow accumulation and snow melting with high discreteness, accuracy and promptness. Within the framework of implementing the initiated project, a snow-pillow prototype was created based on analogue strain-measuring sensors working in conjunction with an accumulating mechanism and a digital indicator run via a microcontroller. Subject to agreement with the directorate of the Federal State Budgetary Institution "Bashkir UGMS", the snow-pillow prototype was installed on the territory of the meteorological station Ufa-Dema in November 2019. Placing the pillow at the active weather observation station allows comparing the results obtained from the prototype with the data obtained at the station. Comparing the observation results for the autumn-winter season of 2019 has allowed us to conclude that the results obtained at the snow pillow are in line with the data of instrumental observations. The operating experience of the snow pillow shows that the prototype created under the project is applicable for evaluating the snow water equivalent, provided some minor changes are introduced into the design. In the future, observation results obtained from a network of snow pillows can be used for adjusting analytical models of snow accumulation and melting within the territory.
\end{abstract}

\section{Introduction}

A snow-pillow (or snow-measuring pillow, hereinafter referred to as SP) is an appliance designed for precise determining the snow water equivalent in the snow cover.

The initial attempts to create snow pillows date back to the 1960s and the 1970s. The first snow pillows were installed in the Mount Hood area (Mount Hood, Oregon, USA). The earliest research work pertained to methodological fundamentals of usage, design peculiarities and SP accuracy assessment [1]. Further studies sought to investigate the expansion of snow pillow networks as well as their distribution in other regions [2 - 4], a

\footnotetext{
* Corresponding author: minnegaliev.aleksandr@rambler.ru
} 
number of research works featured SP accuracy comparison and other methods of estimating the snow water equivalent [5-7].

Among the works of Russian authors, we are bound to refer to an article [8] that is likely to describe one of the first prototypes of a snow pillow installed in the Russian Federation. A weight snow pillow with 4 bellows-type strain gauges was applied to obtain information on the dynamics of changes in snow loads for a single snowfall with a view to estimate the odds of potential roof collapsing of buildings and various facilities. A special remote monitoring system worked out by the authors was designed for a load not exceeding $100 \mathrm{kgf} / \mathrm{m}^{2}$ and therefore required cleaning the platform after each snowfall. Consequently, given the above goals and operational features, the aforementioned system cannot serve as a complete analogue of the snow pillow prototype created by the authors of this article.

Currently, two main types of snow pillow design are differentiated: liquid and weight (non-liquid) [9]. The liquid type pillow is a bedding of predominantly rounded shape, made of polyurethane, rubber, neoprene or another elastic waterproof material. The pillow is filled with antifreeze [9], snow weight is determined by recalculating the liquid pressure in accordance with the readings of the built-in sensor. The advantages of liquid pillows lie in the simplicity of design and a relatively high accuracy when applied at high altitude of snow cover. Among the shortcomings there should be noted the necessity of using large amounts of quite expensive and environmentally hazardous antifreeze (more than 700 litres for a snow pillow of the most common diameter of $3 \mathrm{~m}$ ), unstable operating in autumn and spring. During the periods of melting and snow cover formation, as well as under low snow intensity the liquid type pillow tends to provide less accuracy, since the significant temperature amplitudes observed at this period cause liquid compression and dilation, leading to incorrect measurement results [9].

Non-liquid snow pillows are represented by a square (less frequently triangular) platform mounted on weight sensors [10]. In order to reduce the influence of snow bridges and to facilitate the movement in the vertical direction around the platform, an edging of sheet material is installed [10]. Weight snow pillows feature greater accuracy and a more compact size than their liquid counterparts. Among the disadvantages of non-liquid pillows we should mention a rather high cost and design complexity.

Irrespective of the type of construction, the main advantages of the SP (compared to other methods of determining the snow water equivalent) are the ability to obtain data of almost any discreteness and a fairly high autonomy of installation. The disadvantages consist in high costs and a rather high installation complexity. In addition, the absence of measuring instruments of this kind in the state register of the Russian Federation significantly complicates the calibration process conducted in certified laboratories and does not allow obtaining a verification certificate.

In November 2019, the academic staff of the Geography Department of the Bashkir State University and researchers from the Ufa Federal Research Centre of the Russian Academy of Sciences, with the assistance of engineering and technical personnel of the Federal State Budget Institution "Bashkir hydrometeorology and environmental monitoring directorate", assembled a prototype of a weight snow pillow on the territory of the UfaDema meteorological station.

\section{Methods}

The SP prototype is built as a wooden frame with a size of $1500 * 1500 \mathrm{~mm}$ using a wooden bar with a cross-section of $40 * 60 \mathrm{~mm}$. The frame consists of 4 separate parts for the sake of easiness in transportation and hauling, mated by means of a threaded connection during installation. Owing to the design features, in the central part of the frame there remains a square hole with a size of $1000 * 1000 \mathrm{~mm}$ in the clear. This hole is subsequently 
used to install the platform and ensures its free vertical movement under the action of the accumulated snow. The parts of the frame surrounding the platform section and forming a buffering are veneered with plywood $5 \mathrm{~mm}$ thick, fastened to the frame with a nonseparable connection.

The Zemic L6E3 analogue single-point strain sensor was used as a weight measuring sensor. To install the sensor in the frame, a mounting unit was used, which is composed of two square metal plates made of sheet steel with a size of $400 * 400 \mathrm{~mm}, 5 \mathrm{~mm}$ thick, with holes for attaching the sensor and mounting to the frame. The mounting unit allows securely fixing the sensor to the base, as well as firmly installing the platform in relation to the frame, and at the same time the load in the "frame - sensor" and "sensor - platform" junctions is reduced. The SP is installed in an open area, approximately $30 \mathrm{~m}$ north of the existing meteorological station.

Reading the values of snow cover weight is carried out every 2 nd or 3 rd day with a period of 18 hours. A wired analogue-to-digital converter with an LCD is used to record the values.

SP calibration was performed by specialists of the State regional centre for standardization, metrology and testing of the Republic of Bashkortostan after the platform's installation at the permanent operational location. All snow cover weight values collected at the pillow were henceforth recalculated according to the calibration curve (Fig. 1). A critical overview of the calibration results revealed that the largest value obtained for deviation from the standard values $(220 \mathrm{~kg})$ is $+10.08 \mathrm{~kg}$, the average deviation in the interval $0-350 \mathrm{~kg}$ reaches $+3.30 \mathrm{~kg}$. The normalizing of the values as to the area and converting the values to the snow water equivalent indicate that in the first case the deviation will be $10 \mathrm{~mm}$ of the layer, while in the second it makes $3.3 \mathrm{~mm}$, which is considered an acceptable result.

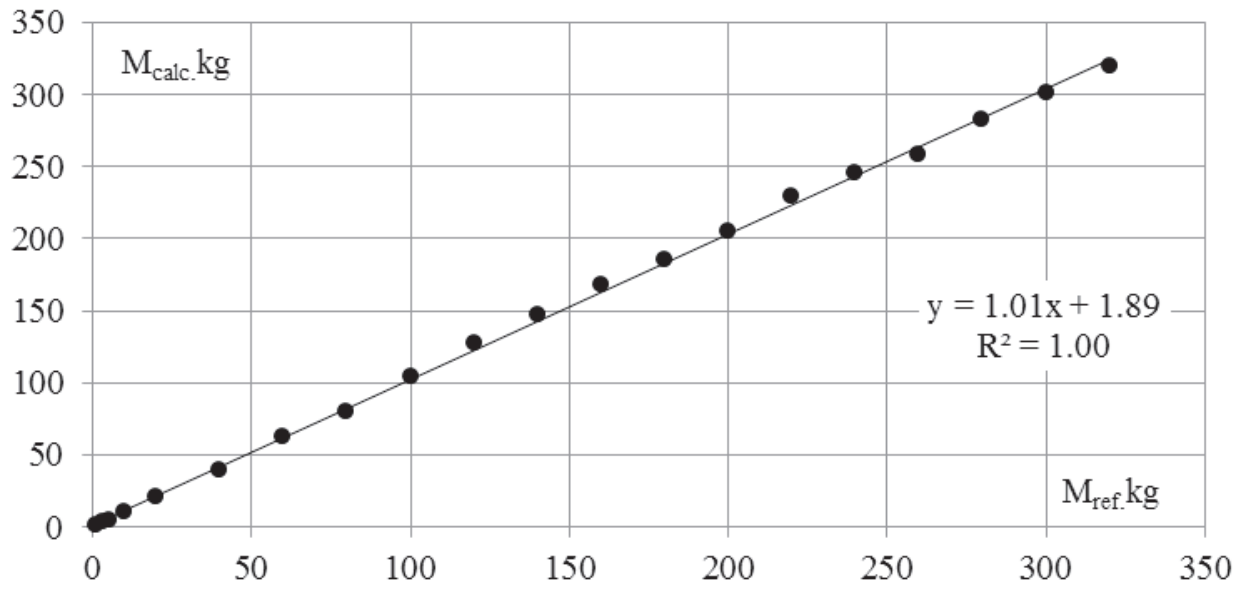

Fig. 1. A calibration curve for the snow pillow prototype. The curve is obtained by juxtaposing the reference weights $\left(\mathrm{M}_{\mathrm{ref} .}\right)$ with the values obtained from the SP (Mcalc.).

In order to provide supplementary assessment of the SP accuracy and in accordance with the recommendations of [7] point-by-point measurements of the snow water equivalent in the snow cover were carried out using the hand-held weight snow meter VS-43. The measurement was carried out on the days of snow surveys at the station (on the 10th, 20th, 30th day of each month), snow samples were collected at each survey point at the site near the location of the SP (at a distance of no more than 5-10 m from the platform). Due to organizational issues the estimation of snow water equivalent by applying a hand-held weight snow meter was carried out only in the period from 
November 4, 2019 to December 31, 2019, only 5 samples being collected. The results of comparing the reference measurements with the values taken on the SP present ambiguity due to the incorrectly selected location for the weight sampling.

\section{Results}

Applying the SP has provided 18 values of snow cover weight, which were further compared with the results of standard precipitation surveillance, obtained using the Tretyakov precipitation-measuring buckets as well as with the snow cover depth values obtained with a fixed depth-gauge (Fig. 2).
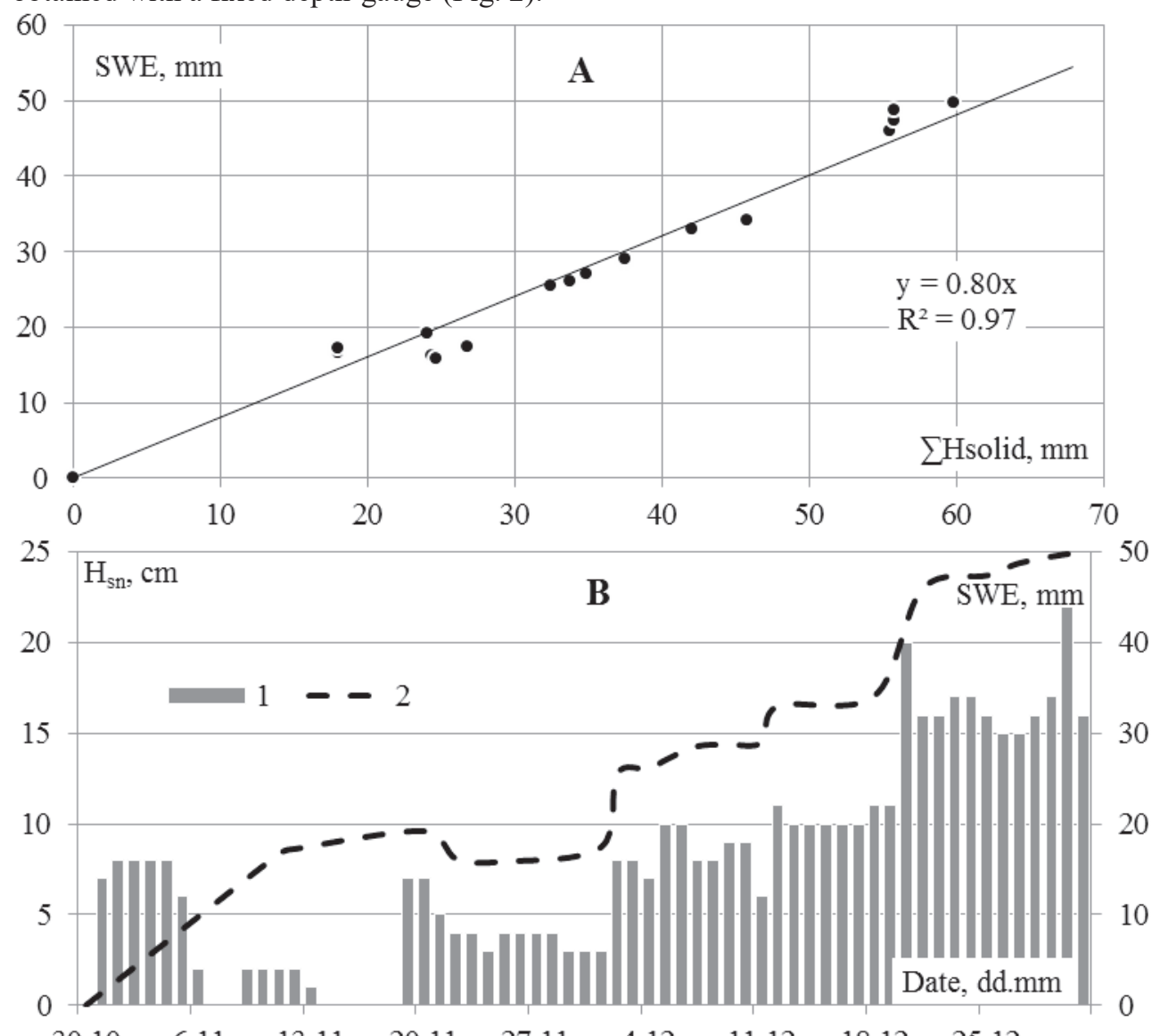

$\begin{array}{lllllllll}30.10 & 6.11 & 13.11 & 20.11 & 27.11 & 4.12 & 11.12 & 18.12 & 25.12\end{array}$

Fig. 2. Comparison of the readings obtained from the SP prototype with the meteorological parameters identified according to standard observations at the meteorological station Ufa-Dema. A) a graph illustrating the relationship between the snow water equivalent according to the snow pillow (SWE) and the accumulated amount of solid precipitation according to the Tretyakov precipitation meter $\left(\sum \mathrm{H}_{\text {solid }}\right)$.

B) combined graph of the daily snow depth values using a fixed depth-gauge $\left(1, \mathrm{H}_{\mathrm{sn}}\right)$ and the snow water equivalent in the snow cover according to the snow pillow data (2, SWE).

The analysis of the results of observations at the Ufa-Dema station reveals that in terms of snow cover formation and the thermal regime the autumn-winter season of 2019-2020 was characterized by significant deviations from the mean multiannual values. A consistent transition of air temperatures through $0^{\circ} \mathrm{C}$ occurred on the $1^{\text {st }}$ of November, the mean 
multiannual value being the $20^{\text {th }}$ of October (hereinafter we refer to the norms for the period 1988-2018). The air temperature curve for the transition period was marked by sharp returns to positive daily values three more times: during the continuous period from the $5^{\text {th }}$ of November to the $8^{\text {th }}$ of November with the accumulated sum of positive daily temperatures of $15.3^{\circ} \mathrm{C}$; during the continuous period from the $13^{\text {th }}$ of November to the $14^{\text {th }}$ of November with the accumulated sum of positive daily temperatures of $3.4^{\circ} \mathrm{C}$, the mean daily temperature for November 18 being $+0.3^{\circ} \mathrm{C}$. Against the backdrop of the repeated returning of positive temperatures, the eventual transition to sub-zero temperature occurred only on the $1^{\text {st }}$ of November, which was 10 days earlier from the date of the multi-annual norm. The formation of snow cover was recorded on November $19^{\text {th }}$. Given the unstable thermal conditions accompanied by a sufficiently early transition through $0^{\circ} \mathrm{C}$ and belownormal rainfall values, snow cover formation and snow cover depth accumulation occurred rather slowly and unevenly. Thus, the snowfall value for November was only $3 \mathrm{~cm}$, the norm being $10 \mathrm{~cm}$, while in December the snowfall value was $12 \mathrm{~cm}$, the norm being 24 $\mathrm{cm}$.

The peculiarities of meteorological regime for the study period resulted in rather complicated operating conditions of the SP prototype. The abrupt changes in temperature and humidity led to the formation of glaze icing and rime ice layers on the surface of the platform and a subsequent increase in its weight even prior to snowfalls. The depletion of snow following the formation of a stable snow cover led to the formation of snow crust and snow-ice bridges between the platform and the buffer zone, which, in turn, resulted in underestimating weight values during the period of primary snow accumulation. The slow accumulation of snow depth and snow water equivalent led to the fact that at the end of December the value of the snow cover weight amounted to $49.8 \mathrm{~kg}$, with the estimated load on the platform being $350 \mathrm{~kg}$. This has hindered determining the features of the prototype at high values of snow load.

On the whole, the snow cover weight values taken from the pillow show a quite close correlation with the accumulated amount of precipitation according to the Tretyakov precipitation gauge (Fig. 2A). In the meantime, the pillow tends to slightly overestimate the snow water equivalent values, which can be accounted for by the influence of glaze icing and rime ice layers accumulated on the surface of the platform. In addition, the overestimated values may be observed due to a snowdrift transfer, which is not taken into account by the pillow. In turn, comparing the results of observations on the prototype with the daily snow depth values using a fixed depth-gauge (Fig. 2B) also displays a considerably high degree of convergence.

\section{Conclusions}

According to the results of the prototype's operation in the autumn-winter season of 2019 2020, a number of specific measures were identified to optimize the SP design.

Despite rather large dimensions of the upper plate of the mounting unit and the structural reinforcement of the platform with ribbing, during its operation a significant amplifying skew of the weight platform has been traced. Therefore, in the future it is planned to increase the number of sensors to four (to provide uniform distribution of the load) and to replace the plywood platform material with a $5 \mathrm{~mm}$ thick aluminium sheet. In addition, the mechanism for collecting snow cover weight values is to be optimized. Currently, the values are read using an analogue-to-digital LCD converter requiring the presence of a specialist at the SP location. In the meantime, the time for taking values is determined arbitrarily and is confined mainly to precipitation and thaws. Currently, the group's specialists have developed and tested a logger featuring a built-in modem and a 
self-contained source of power supply. The logger allows reading and accumulating data of the desired resolution and transmitting information via mobile communication networks.

In general, despite variable meteorological conditions, difficulties with installation and calibration as well as some design flaws, the installed prototype provided sufficiently high accuracy and functionality, based on the results of operation during the period of snow accumulation. Using the results of observations obtained from the SP will further make it possible to clarify the features of the snow accumulation process and to adjust the calculated snow melting patterns for the territory.

Data collection and primary processing was performed by Ruslan Rakhimov. The research framework, design elaboration, and statistical data processing were conducted by Aleksandr Minnegaliev. The writing and editing of the article are shared equally by all authors.

The authors express gratitude to A. Gareyev (Bashkir State University), V. Gorokholskaya, A. Kozyaeva and E. Khasanova for their contribution to the process of conducting observations.

\section{References}

1. R. T. Beaumont, J. of Appl. Meteorol., 4 (1965)

2. P.Y. Bernier, Nord. Hydrol., 17 (1986)

3. H.K. Sorteberg, R.V. Engeset, H.C. Udnaes, Phys. Chem. Earth C Sol. Terr. Planet Sci., 26, 10-12 (2001)

4. J.I. Lopez Moreno, B. Alvera, J. Latron, S.R. Fassnacht, Cuad. de Investig. Geogr., 36 (2010)

5. R.T. Beaumont, Phys. Snow Ice, 1 (1967)

6. J.B. Johnson, D. Marks, Hydrol. Process., 18 (2004)

7. C. D. Smith, A. Kontu, R. Laffin, J.W. Pomeroy, Cryosphere, 11 (2017)

8. V.A. Lobkina, I. A. Kononov, A. A. Potapov, Ice Snow, 56, 2 (2016)

9. D.M. Gray, D.H. Male, Pergamon Press (1981)

10. J.B. Johnson, A.B. Gelvin, P. Duvoy, G.L. Schaefer, G. Poole and G. D. Horton, Hydrol. Process., 29 (2015) 